Research Article

\title{
A Computational Method for Dynamic Analysis of Deployable Structures
}

\author{
Ying Wang and Bin Sun \\ Department of Engineering Mechanics, Jiangsu Key Laboratory of Engineering Mechanics, Southeast University, \\ Nanjing 210096, China \\ Correspondence should be addressed to Bin Sun; binsun@seu.edu.cn
}

Received 21 February 2020; Revised 6 May 2020; Accepted 3 June 2020; Published 27 June 2020

Academic Editor: Giuseppe Piccardo

Copyright (c) 2020 Ying Wang and Bin Sun. This is an open access article distributed under the Creative Commons Attribution License, which permits unrestricted use, distribution, and reproduction in any medium, provided the original work is properly cited.

\begin{abstract}
A computational method is developed to study the dynamics of lightweight deployable structures during the motion process without regard to damping. Theory and implementation strategy of the developed method are given in this study. As a case study, the motion process of a bar-joint structure and a ring array scissor-type structure was simulated under external dynamic loading. In order to verify the effectiveness of the method, the simulation results are compared with the results predicted by the authenticated multibody system dynamics and simulation program. It shows that the method is effective to dynamic analysis of deployable structures no matter the structures are rigid or elastic. Displacement, velocity, and acceleration for the entire deployable structures during the motion process can be computed, as well as strain if the deployable structure is elastic.
\end{abstract}

\section{Introduction}

Due to their excellent properties, such as being convenient for transportation and construction, high efficiency, and reutilization, deployable structures offer a new structural engineering design and have been widely used in aerospace, civil engineering, and in other areas [1-7], which are different from traditional constructional methods. At present, the research of deployable structure mainly focuses on the geometric configuration and dynamic and static characteristics of the structure and has achieved a lot of high-level research results [8]. For example, Wei et al. analyzed mobility and geometric characteristics of the Hoberman switchpitch ball [9]. Sun et al. studied the kinematics, dynamics, and mobility of the deployable scissor structures using the modified screw theory $[10,11]$. Tanaka et al. developed a two-dimensional 8-bar jointed structure and analyzed its dynamic characteristics [12]. Muvengei et al. studied the dynamic behavior of planar rigid-body systems using the fine model for considering dynamic interaction of multiple revolute joints with clearances [13]. Although such excellent research works have reached a relatively high degree of maturity, there are still many new questions in need of solution, and their many design concepts and computational methods are still not fully accepted as a feasible engineering solution, especially for lightweight deployable structures under dynamic loading, since their structural damping is generally low, and there will be a challenge when they are subjected to dynamic loading [14].

Due to their benefits, there are many lightweight deployable structures such as tensegrity structures, which are a kind of pin-jointed structures composed of struts (in compression) and tendons (in tension) [15-17]. The dynamic behavior of tensegrity structures is still being widely studied due to its importance [14]. Sultan et al. developed linearized motion models for certain tensegrity structures and studied their dynamic behavior [18]. Cheong et al. developed a computational method for the dynamic analysis of a tensegrity structure by using nonminimal coordinates [19]. Nagase and Skelton presented the motion equations for dynamic analysis of tensegrity structures [20]. Oliveto and Sivaselvan developed a method for dynamic analysis of a tensegrity system restricted to small-deformation analysis based on a complementarity framework [21]. 
The main objective of this work is to develop an efficient computational method for dynamic analysis of lightweight deployable structures including but not limited to tensegrity structures, which can be used to study their dynamic characteristics for better structural design. Compared to the previous works [22], the novelty of the developed method is that the method can be used to deformation, kinematic, and dynamic analyses of deployable structures, no matter the deployable structure is a stable structure or mechanism. In order to determine the motion process of deployable structures under external dynamic loading, displacement, velocity, and acceleration of the deployable structure during the expansion and compression process can be computed using the developed method. In order to verify effectiveness of the developed method, a simple bar-joint structure is studied and analyzed. And the simulation results are compared with the numerical results predicted by ADAMS (Automatic Dynamic Analysis of Mechanical Systems), which is an authenticated multibody system dynamics and simulation software. Lastly, as a case study of application, the motion process of a ring array scissor-type deployable structure including displacement, velocity, and acceleration, as well as strain, is studied and analyzed under external dynamic loading.

\section{Governing Equations for the Motion Process of Lightweight Deployable Structures}

This study aims to develop a computational method to analyze the dynamics of lightweight deployable structures with low structural damping during the expansion and compression process. Since bar-joint structures is one of the most common types of deployable structures [23], here we take a bar-joint structure as an example to describe the governing equations of the developed method in this section, which contain link members and revolute joints allowing a relative rotation shown in Figure 1.

The equations of motion for deployable structures can be expressed in global coordinates as follows:

$$
\mathbf{M}_{g} \ddot{d}_{g}(t)+\mathbf{C}_{g} \dot{d}_{g}(t)+\mathbf{K}_{g} \mathbf{d}_{g}(t)=\mathbf{F}_{\mathbf{b}}(t)
$$

where $\mathbf{M}_{g}$ are the mass matrices, $\mathbf{C}_{g}$ are damping matrices, $\ddot{d}_{g}(t), \dot{d}_{g}(t)$, and $\mathbf{d}_{g}(t)$ are, respectively, the acceleration, velocity, and displacement vectors of the structure at time $t$, $\mathbf{F}_{\mathbf{b}}(t)$ is the external dynamic loading, and $\mathbf{K}_{g}$ are global stiffness matrices of the structure. In this study, only deployable structures with low structural damping have been paid attention to, so equation (1) does not require the damping matrix and can be rewritten as

$$
\mathbf{M}_{g} \ddot{d}_{g}(t)+\mathbf{K}_{g} \mathbf{d}_{g}(t)=\mathbf{F}_{\mathbf{b}}(t) \text {. }
$$

The global mass $\mathbf{M}_{g}$ and stiffness $\mathbf{K}_{g}$ matrices can be calculated by combining all individual elements mass $\mathbf{M}_{e}$ and stiffness $\mathbf{K}_{e}$ matrices described in global coordinate. Here, each link member denoted as $m$ with length $l$ shown in
Figure 1 can be defined as an element, and the notations of the element can also be found in Figure 1. The element has two nodes $i$ and $j . \mathbf{X}_{i}=\left(x_{i}, y_{i}\right)$ and $\mathbf{X}_{j}=\left(x_{j}, y_{j}\right),\left(F_{x i}^{m}, F_{y i}^{m}\right)$ and $\left(F_{x j}^{m}, F_{y j}^{m}\right)$, and $\left(v_{i}^{m}, u_{i}^{m}\right)$ and $\left(v_{j}^{m}, u_{j}^{m}\right)$ are, respectively, global Cartesian coordinate vectors, force vectors, and displacement vectors of the two nodes $i$ and $j . \theta^{m}$ is the angle between the link member $m$ and $x$-axis. The mass $\mathbf{M}_{e}$ and stiffness $\mathbf{K}_{e}$ matrices for the element can be described as in global coordinate:

$$
\begin{aligned}
& \mathbf{M}_{e}=\mathbf{T}_{e}^{\mathrm{T}} \frac{\rho A l}{6}\left[\begin{array}{cccc}
2 & 0 & 1 & 0 \\
0 & 2 & 0 & 1 \\
1 & 0 & 2 & 0 \\
0 & 1 & 0 & 2
\end{array}\right] \mathbf{T}_{e}, \\
& \mathbf{K}_{e}=\mathbf{T}_{e}^{\mathrm{T}} \frac{E A}{l}\left[\begin{array}{cccc}
1 & 0 & -1 & 0 \\
0 & 0 & 0 & 0 \\
-1 & 0 & 1 & 0 \\
0 & 0 & 0 & 0
\end{array}\right] \mathbf{T}_{e},
\end{aligned}
$$

where $\rho, A$, and $E$ are, respectively, the density, crosssectional area, and elastic modulus of the link member. $\mathbf{T}_{e}$ is transformation matrix from local Cartesian coordinates to global Cartesian coordinates and can be expressed as

$$
\mathbf{T}_{e}=\left[\begin{array}{cccc}
\cos \theta^{m} & \sin \theta^{m} & 0 & 0 \\
-\sin \theta^{m} & \cos \theta^{m} & 0 & 0 \\
0 & 0 & \cos \theta^{m} & \sin \theta^{m} \\
0 & 0 & -\sin \theta^{m} & \cos \theta^{m}
\end{array}\right] .
$$

\section{Implementation Strategy for Dynamic Analysis of Deployable Structures Using the Developed Method}

Here, the following equations are used to solve equation (2) which controls the motion process of lightweight deployable structures without regard to structural damping in this study $[24,25]$ :

$$
\begin{aligned}
\mathbf{d}_{g}(t+\Delta t)= & \mathbf{d}_{g}(t)+\dot{d}_{g}(t) \Delta t \\
& +\left[\frac{1}{2} \ddot{d}_{g}(t)+\alpha\left(\ddot{d}_{g}(t+\Delta t)-\ddot{d}_{g}(t)\right)\right] \Delta t^{2}, \\
\dot{d}_{g}(t+\Delta t)= & \dot{d}_{g}(t)+\left[(1-\delta) \ddot{d}_{g}(t)+\delta \ddot{d}_{g}(t+\Delta t)\right] \Delta t,
\end{aligned}
$$

where $\Delta t$ is the interval time integration and $\alpha$ and $\delta$ are model parameters.

Based on equations (6) and (7), the recursive form of equation (2) can be expressed as follows: 


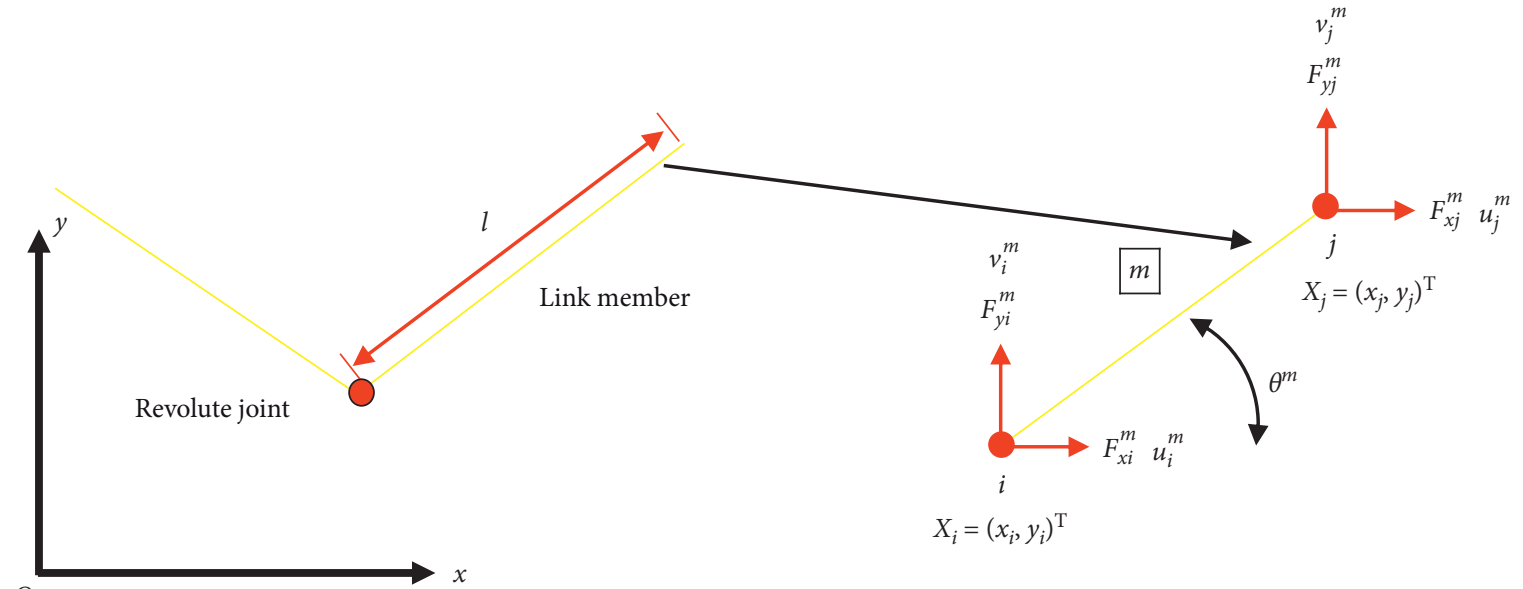

FIgURE 1: Notations of a simple bar-joint structure.

$$
\begin{aligned}
\left(\frac{1}{\alpha \Delta t^{2}} \mathbf{M}_{g}+\mathbf{K}_{g}\right) \mathbf{d}_{g}(t+\Delta t)= & \mathbf{F}_{\mathbf{b}}(t+\Delta t)+\left(\frac{1}{2 \alpha}-1\right) \mathbf{M}_{g} \ddot{d}_{g}(t) \\
& +\frac{1}{\alpha \Delta t} \mathbf{M}_{g} \dot{d}_{g}(t)+\frac{1}{\alpha \Delta t^{2}} \mathbf{M}_{g} \mathbf{d}_{g}(t) .
\end{aligned}
$$

Based on the above description in this section, the solution strategy for dynamic analysis of deployable structures using the developed method can be described as follows:

(1) Calculate the global mass $\mathbf{M}_{g}$ and stiffness $\mathbf{K}_{g}$ matrices by combining all individual elements mass $\mathbf{M}_{e}$ and stiffness $\mathbf{K}_{e}$, respectively, as shown in equations (3) and (4).

(2) Set initial vector $\dot{d}_{g}\left(t_{0}\right)$ and $\mathbf{d}_{g}\left(t_{0}\right)$ and calculate $\ddot{d}_{g}\left(t_{0}\right)=\mathbf{M}_{g}^{-1}\left[\mathbf{F}_{\mathbf{b}}\left(t_{0}\right)-\mathbf{K}_{g} \mathbf{d}_{g}\left(t_{0}\right)\right]$.

(3) Choose $\Delta t, \alpha$, and $\delta$ and calculate the following parameters:

$$
\begin{aligned}
& \mathrm{A}_{1}=\frac{1}{\alpha \Delta t^{2}} \\
& \mathrm{~A}_{2}=\frac{1}{\alpha \Delta t} \\
& \mathrm{~A}_{3}=\frac{1}{2 \alpha}-1
\end{aligned}
$$

(4) Calculate the global effective stiffness matrices $\overline{\mathbf{K}}_{g}$ by combining all individual elements' effective stiffness $\overline{\mathbf{K}}_{e}$, which can be expressed as

$$
\overline{\mathbf{K}}_{e}=\mathbf{K}_{e}+\mathbf{K}_{e}^{n}+\mathrm{A}_{1} \mathbf{M}_{e}
$$

where $\mathbf{K}_{e}^{n}$ is caused by nonlinear geometry, which is the contribution of internal forces for the stiffness matrices, and can be expressed as where $F_{e}$ is the axial force of the link member. Note that $\theta^{m}$ should be updated with time $t$ since large rotation condition is considered here.

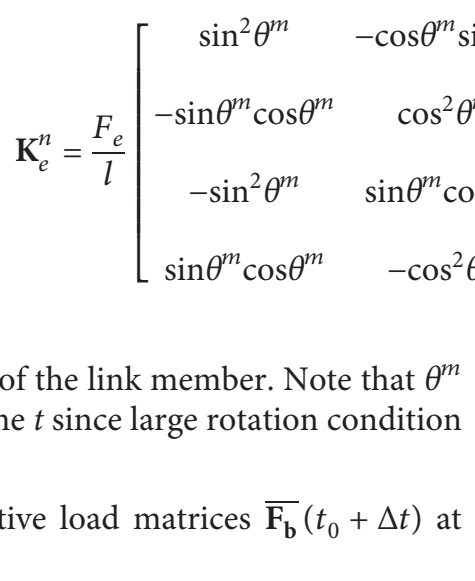

(5) Calculate the effective load matrices $\overline{\mathbf{F}_{\mathbf{b}}}\left(t_{0}+\Delta t\right)$ at time $t_{0}+\Delta t$ :
(6) Calculate the displacement vector $\mathbf{d}_{g}\left(t_{0}+\Delta t\right)$ at time $t_{0}+\Delta t:$ 


$$
\mathbf{d}_{g}\left(t_{0}+\Delta t\right)=\overline{\mathbf{K}}_{g}^{-1} \overline{\mathbf{F}_{\mathbf{b}}}\left(t_{0}+\Delta t\right)
$$

(7) Calculate the acceleration $\ddot{d}_{g}\left(t_{0}+\Delta t\right)$ and velocity $\dot{d}_{g}\left(t_{0}+\Delta t\right)$ vectors at time $t_{0}+\Delta t$ :

$$
\begin{aligned}
\ddot{d}_{g}\left(t_{0}+\Delta t\right)= & \mathrm{A}_{1}\left(\mathbf{d}_{g}\left(t_{0}+\Delta t\right)-\mathbf{d}_{g}\left(t_{0}\right)\right)-\mathrm{A}_{2} \dot{d}_{g}\left(t_{0}\right) \\
& -\mathrm{A}_{3} \ddot{d}_{g}\left(t_{0}\right), \\
\dot{d}_{g}\left(t_{0}+\Delta t\right)= & \dot{d}_{g}\left(t_{0}\right)+\left[(1-\delta) \ddot{d}_{g}\left(t_{0}\right)+\delta \ddot{d}_{g}\left(t_{0}+\Delta t\right)\right] \Delta t .
\end{aligned}
$$

Using the above recursive process, we can calculate the motion process of the deployable structure under external dynamic loading within the whole time history.

\section{Verification of the Developed Method}

In this section, dynamics of a simple bar-joint structure, such as displacement, velocity, and acceleration, are studied. As shown in Figure 2, the simple bar-joint structure is composed of eight nodes and twelve link members. The initial structural geometric size and material properties are given in Figure 2, and the coordinates of all nodes are also given. The cross-sectional area of the link member is $5 \times 10^{-4} \mathrm{~m}^{2}$.The elastic modulus $E$ and density $\rho$ are, respectively, chosen as $2.1 \mathrm{GPa}$ and $7801 \mathrm{~kg} / \mathrm{m}^{3}$ for steel. Boundary conditions and applied loading are also described in Figure 2. Node 1 can rotate but not move. The force of $10 \mathrm{~N}$ is applied on node 8 along $z$ direction. We set initial velocity of all nodes to zero. Here, the values of $\alpha$ and $\delta$ in the method are, respectively, chosen as 0.253 and 0.505 , and the value of $\Delta t$ is chosen as $0.01 \mathrm{~s}$.

The displacement, velocity, and acceleration of the deployable structure during the motion process without regard to gravity are computed using the developed method. In order to verify the effectiveness of the developed method, the simulation results are compared with the numerical results predicted by the authenticated multibody system dynamics and simulation software ADAMS. As shown in Figures 3(a)-3(c), the displacement, velocity, and acceleration of node 8 shown in Figure 2 along $z$ axis, respectively, predicted by the developed method and ADAMS are given. We can find that the simulation results predicted by the developed method and ADAMS are almost unanimous. The transformations of mode shapes for the structure during the motion process are also given in Figure 3(d). It shows that the developed method is effective to analyze the dynamics of the deployable bar-joint structure.

\section{Dynamic Analysis for a Ring Array Scissor- Type Deployable Structure Using the Developed Method}

As a case of application of the developed method, dynamics of a ring array scissor-type deployable structure are numerically analyzed. The initial structural geometric size and material properties of the ring array scissor-type deployable structure are given in Figure 4. As shown in Figure 4, the ring array scissor-

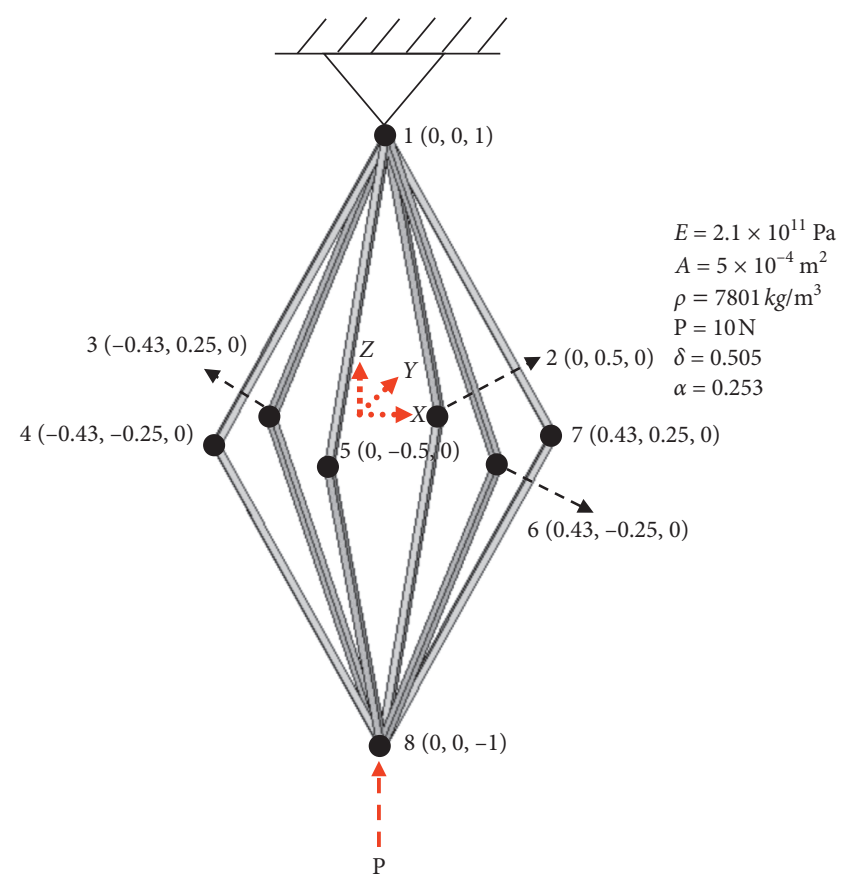

Figure 2: Initial mode shape of the deployable structure.

type deployable structure is composed of six same scissor units in each which four link members with the same length $l$ are connected by a revolute joint for allowing rotation and translation. The angle $\theta$ between two nodes of every scissor unit and origin point $O$ shown in Figure 4 has the same angle, i.e., $\pi / 3$, in the ring array scissor-type deployable structure. The crosssectional area of the link member is $4 \times 10^{-4} \mathrm{~m}^{2}$. The applied loading is also described in Figure 4, which is a decreasing function of time $t$. We set initial velocity of all nodes to zero. As described in Section 4, the elastic modulus $E$ and density $\rho$ are also, respectively, chosen as $2.1 \mathrm{GPa}$ and $7801 \mathrm{~kg} / \mathrm{m}^{3}$ for steel. The values of $\alpha$ and $\delta$ are, respectively, chosen as 0.253 and 0.505 , and the value of $\Delta t$ is chosen as $0.01 \mathrm{~s}$.

The dynamics such as displacement, velocity, and acceleration of the deployable structure during the motion process without regard to gravity are computed using the developed method. As shown in Figures 5-7, the displacement, velocity, and acceleration curves over time of node 1 , node 2 , and node 3 along $x$ axis are predicted by the developed method and given. The transformations of mode shapes for the structure during the motion process for the time $0.2 \mathrm{~s}, 0.6 \mathrm{~s}, 1 \mathrm{~s}, 1.4 \mathrm{~s}$, $1.8 \mathrm{~s}$, and $2.2 \mathrm{~s}$ are also given in Figure 8. It shows that the developed method is also effective to analyze the dynamics of the ring array scissor-type deployable structure. And the displacement, velocity, and acceleration for the entire deployable structures during the motion process can be computed by the developed method. Meanwhile, different from traditional multi-rigid-body system dynamics and simulation program, the developed method can also be used to compute the dynamics of elastic deployable structures, which can be confirmed by this numerical example in this section. As shown in Figure 9, the cloud image for the axial strain of the entire structure during the motion process over time can be computed and given by the developed method. 


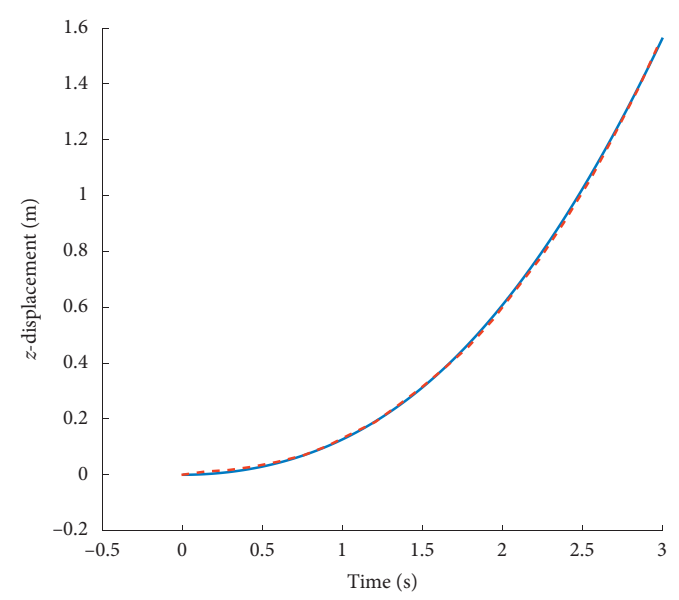

_ Predicted by the developed method

- _ - Predicted by ADAMS

(a)

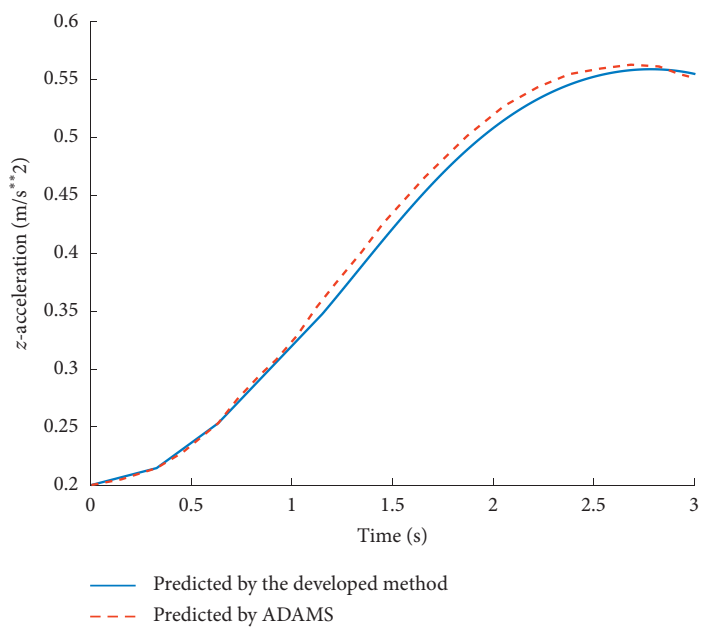

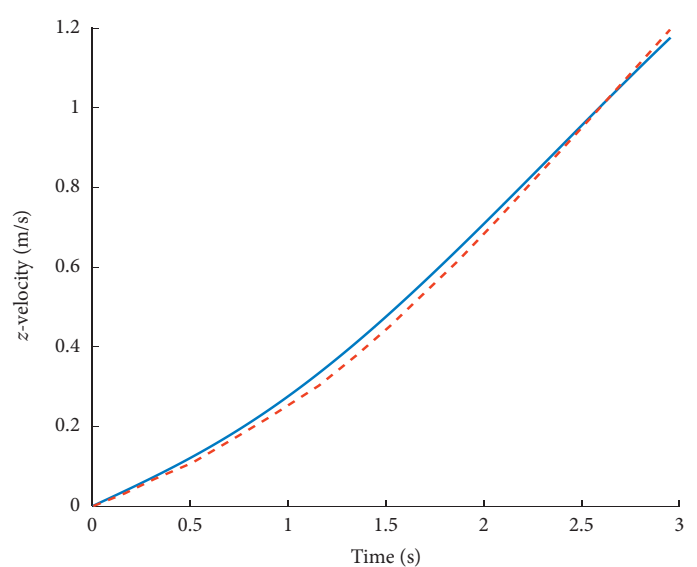

_ Predicted by the developed method - - - Predicted by ADAMS

(b)

Time: 0s

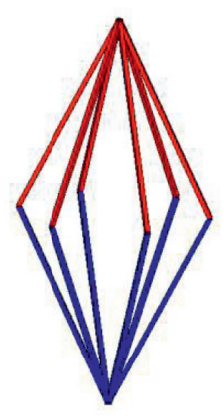

Time: $1 \mathrm{~s}$

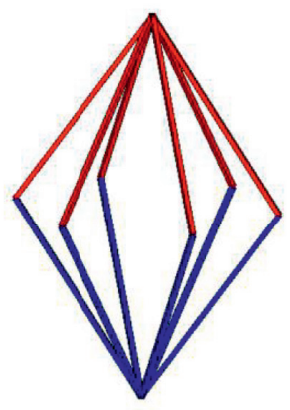

Time: $2 \mathrm{~s}$

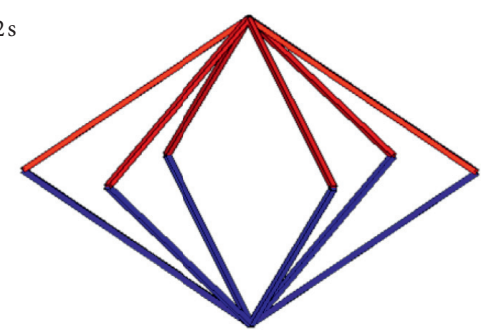

Time: $3 \mathrm{~s}$ 


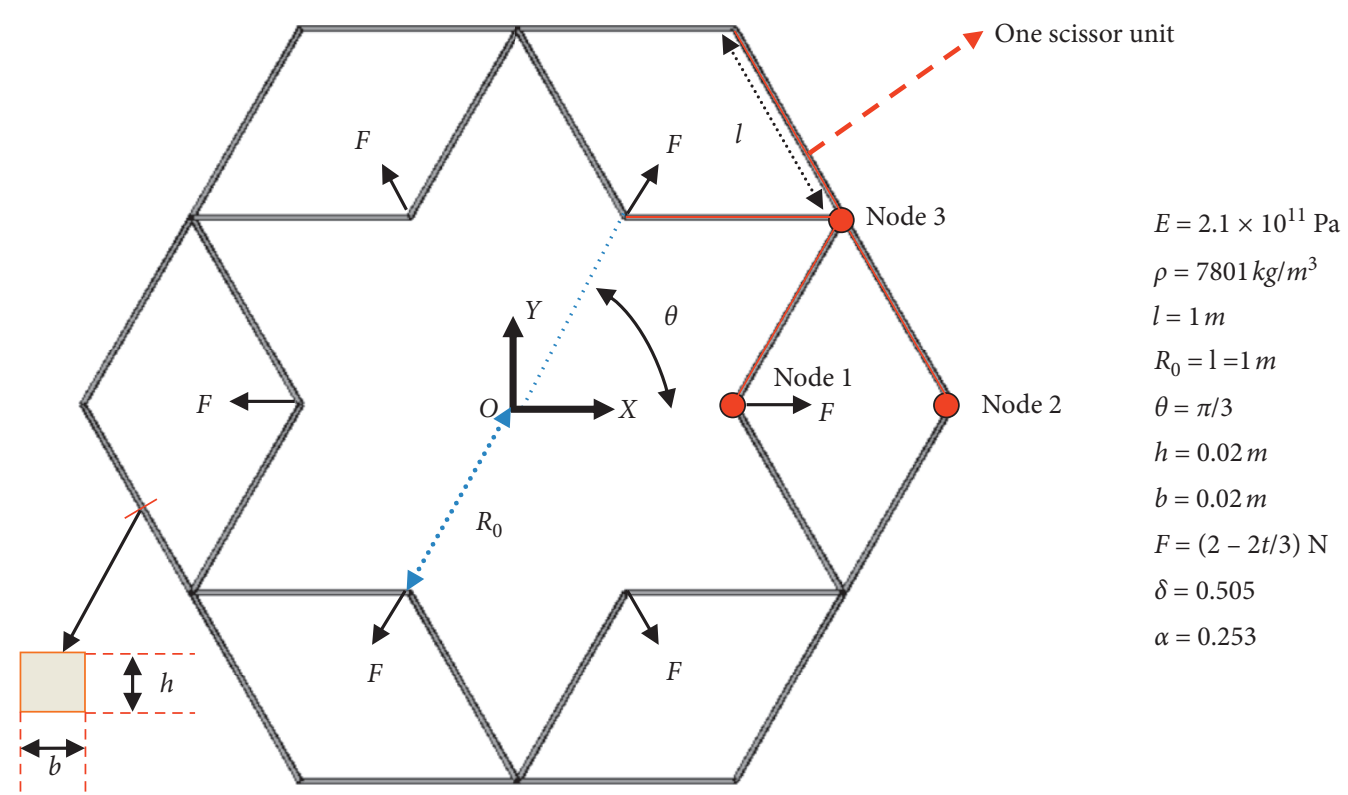

FIgURE 4: Initial mode shape of the ring array scissor-type deployable structure.

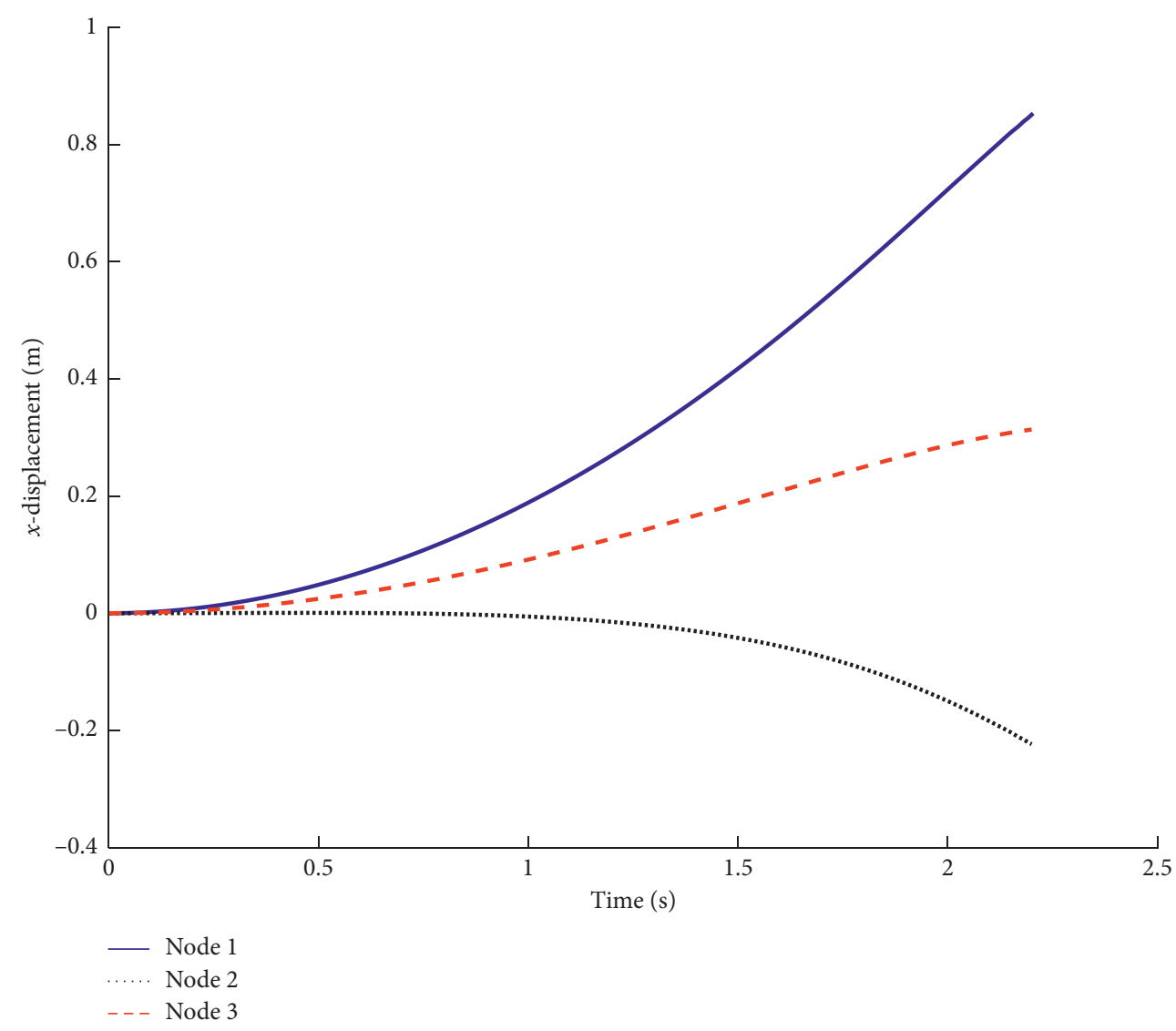

FIgURE 5: Curves of $x$-displacement over time for some nodes in the deployable structure. 


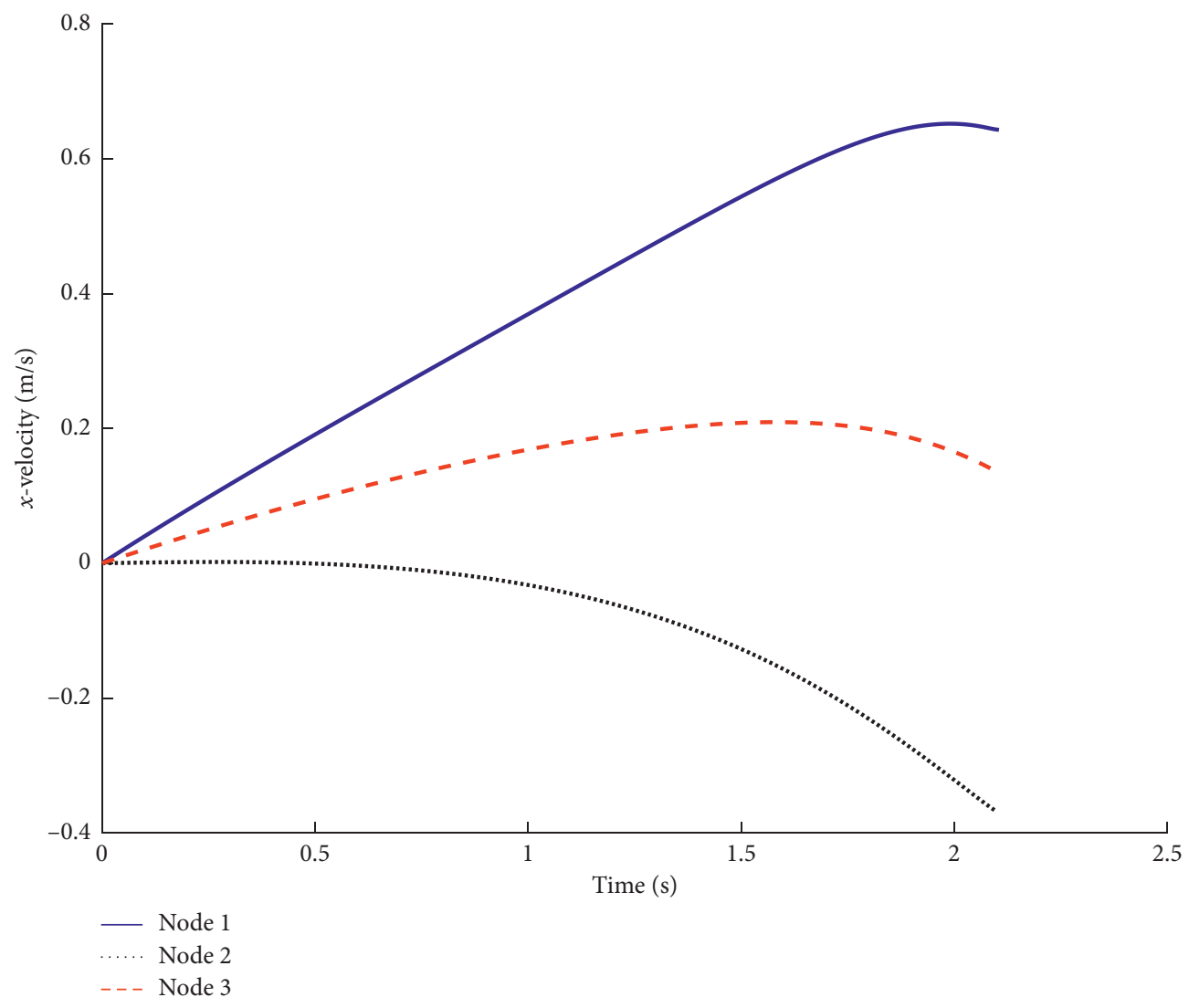

Figure 6: Curves of $x$-velocity over time for some nodes in the deployable structure.

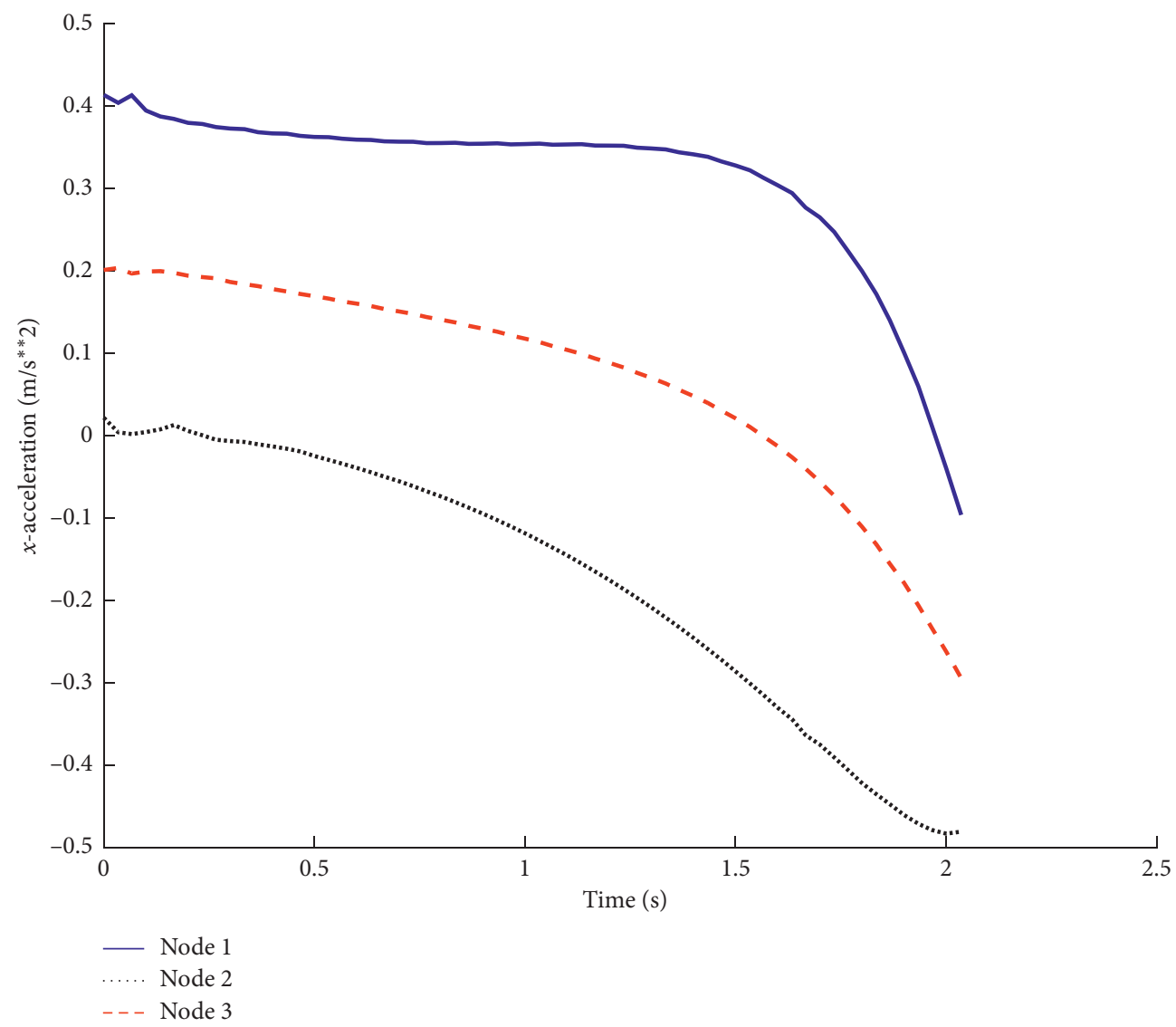

FIgURE 7: Curves of $x$-acceleration over time for some nodes in the deployable structure. 


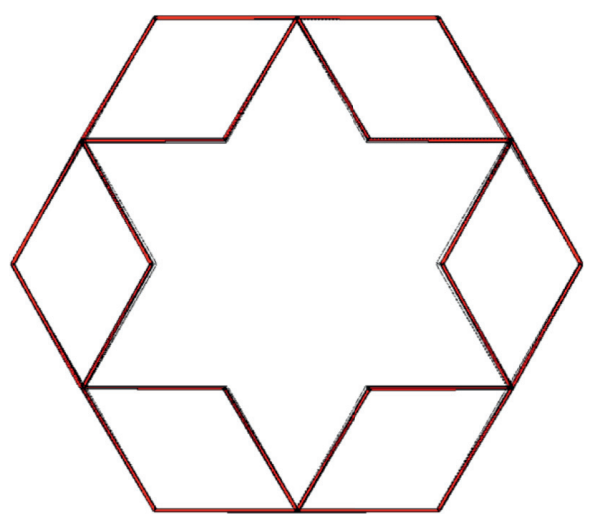

(a)

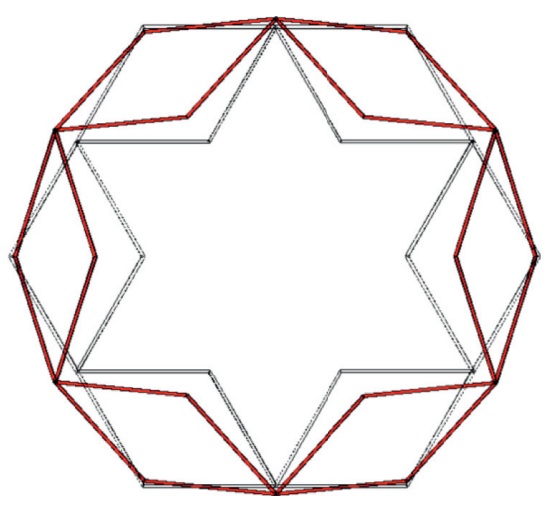

(d)

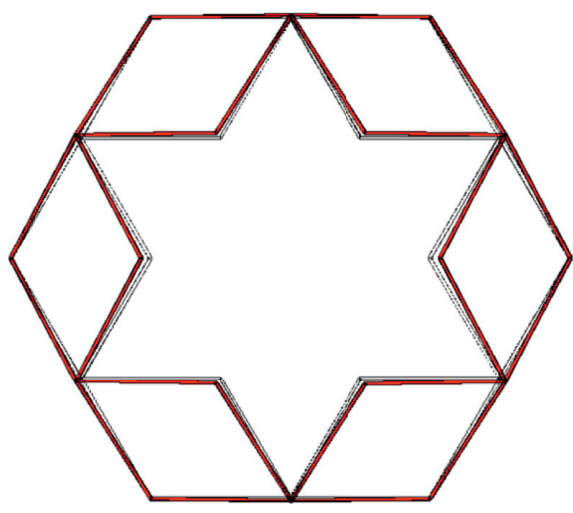

(b)

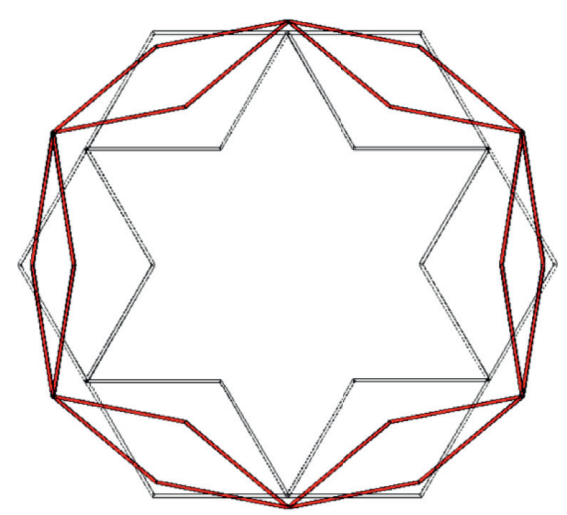

(e)

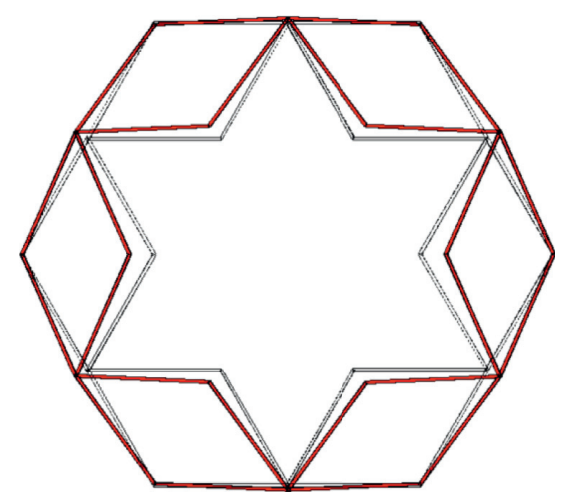

(c)

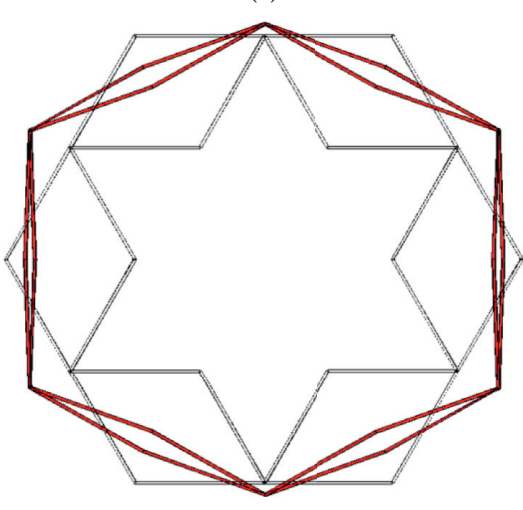

(f)

Figure 8: Transformations of mode shapes for the deployable structure during the motion process. (a) Time: $0.2 \mathrm{~s}$. (b) Time: $0.6 \mathrm{~s}$. (c) Time: $1 \mathrm{~s}$. (d) Time: $1.4 \mathrm{~s}$. (e) Time: $1.8 \mathrm{~s}$. (f) Time: $2.2 \mathrm{~s}$.

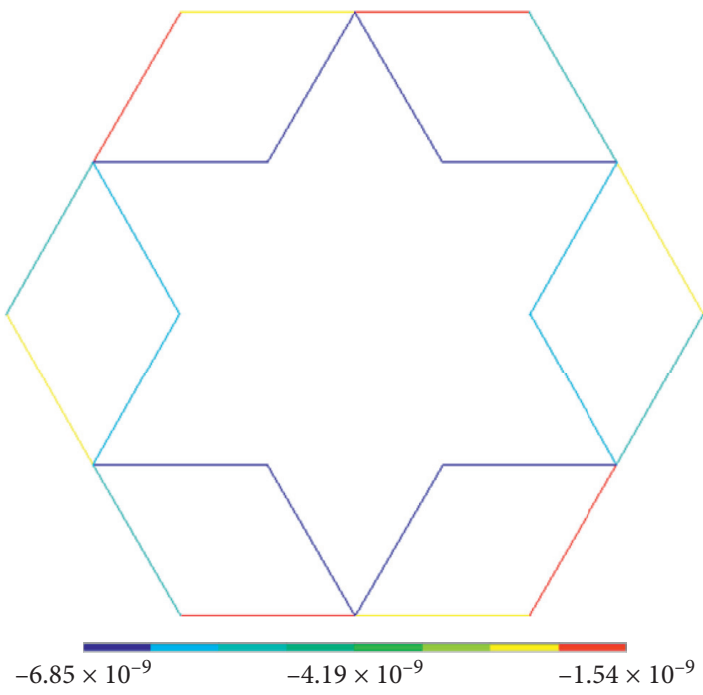

(a)

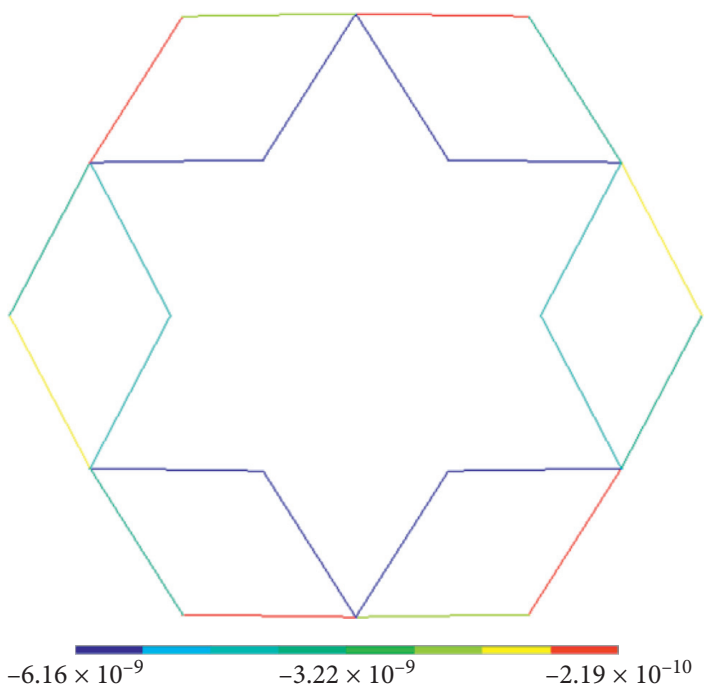

(b)

Figure 9: Continued. 


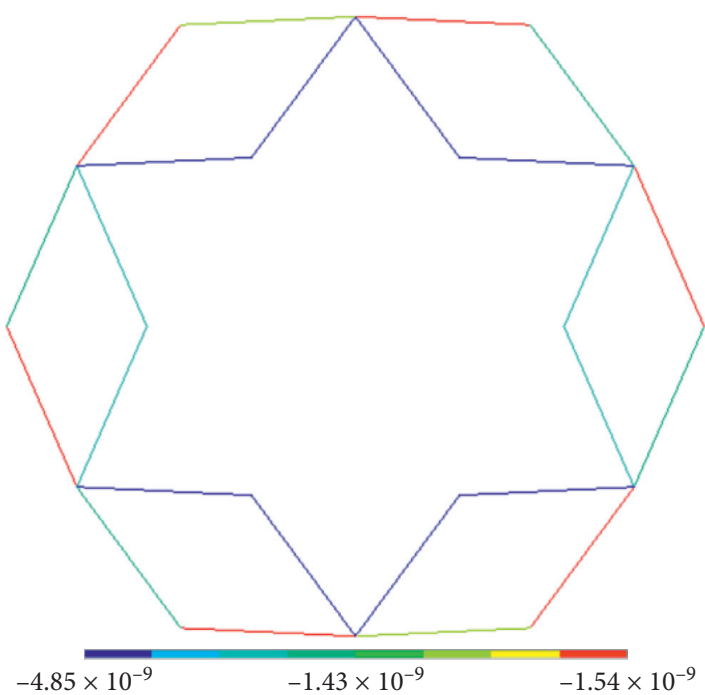

(c)

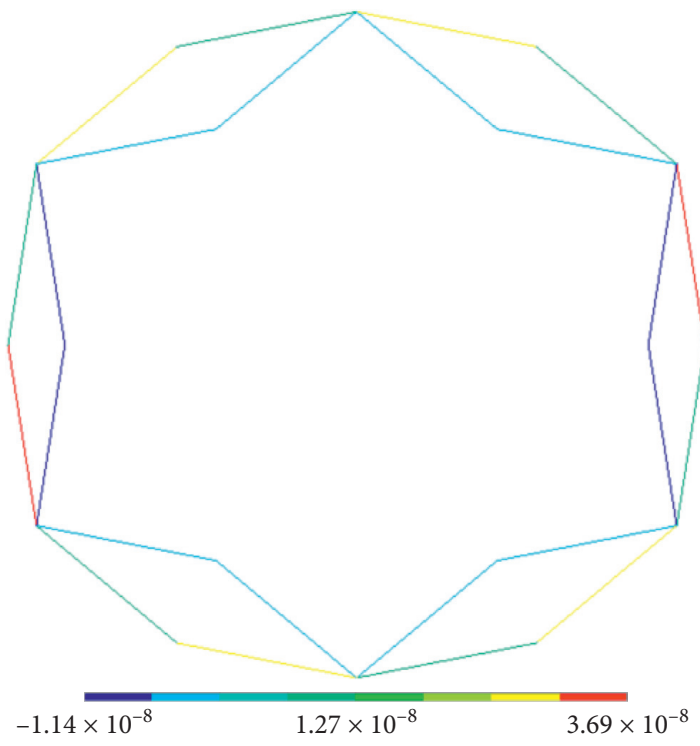

(e)

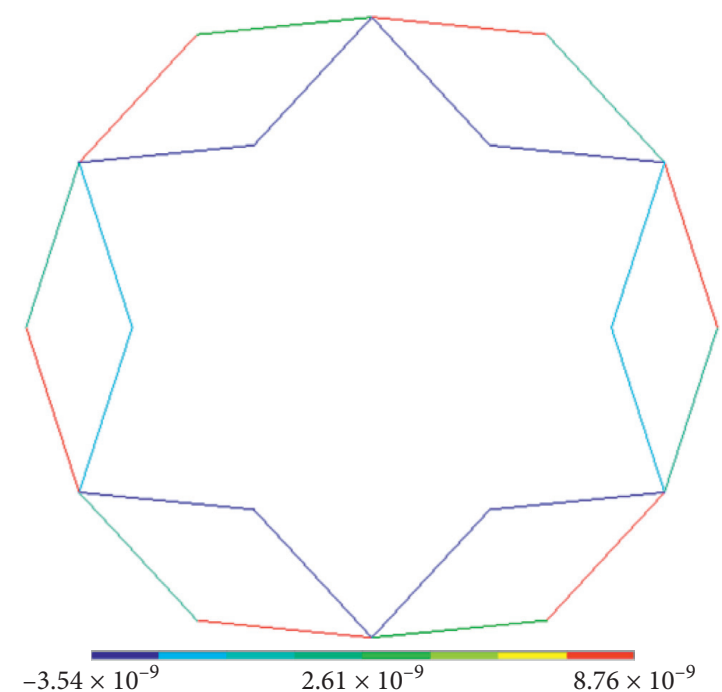

(d)

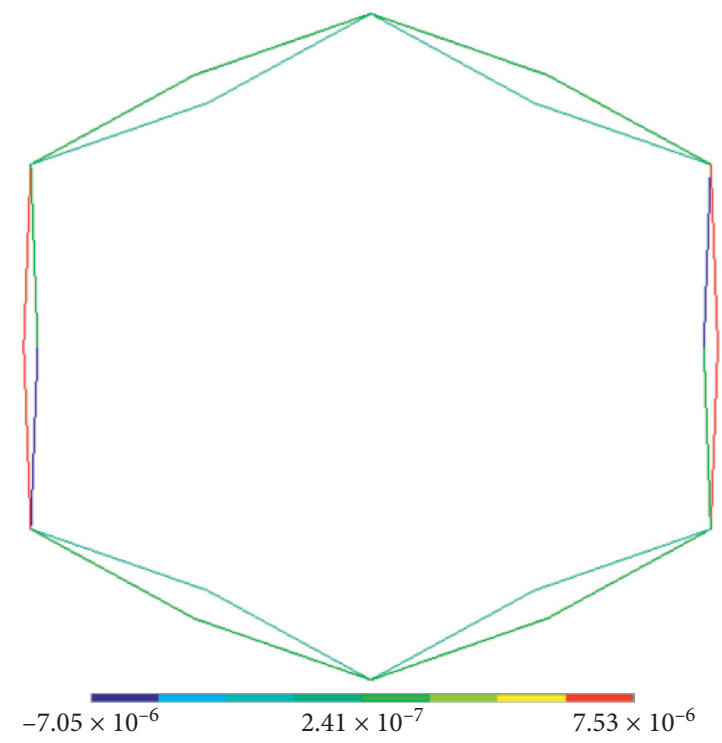

(f)

Figure 9: Axial strain for the deployable structure during the motion process. (a) Time: $0.2 \mathrm{~s}$. (b) Time: $0.6 \mathrm{~s}$. (c) Time: $1 \mathrm{~s}$. (d) Time: $1.4 \mathrm{~s}$. (e) Time: $1.8 \mathrm{~s}$. (f) Time: $2.2 \mathrm{~s}$.

Actually, if the elastic modulus of link member is set to a large enough value, the developed method in this study can also be used to compute the dynamics of the rigid deployable structures. In conclusion, the numerical examples, as described in Sections 4 and 5, demonstrate that the developed method here can be used as an effective numerical tool to compute the dynamics of deployable structures no matter the structures are elastic or rigid.

\section{Conclusions}

The major conclusions can be summarized as follows:

(1) A computational method is developed to compute dynamics of lightweight deployable structures without regard to damping during the expansion or compression process.

(2) As a case study, it shows that dynamics such as displacement, velocity, and acceleration for the entire deployable structures during the motion process can be computed by the method, as well as the strain if the structures are elastic.

(3) By comparison of the numerical results, respectively, predicted by the developed method and ADAMS, it shows that the method is effective for dynamic analysis of the deployable structures.

(4) From the numerical analysis, the developed method is effective for the dynamic analysis of the elastic or rigid deployable structures. 


\section{Data Availability}

All data generated or analyzed during this study are included within the article.

\section{Conflicts of Interest}

The authors declare that they have no conflicts of interest.

\section{Acknowledgments}

This study was financially supported by the National Natural Science Foundation of China (grant no. 51678135), Natural Science Foundation of Jiangsu Province (nos. BK20171350 and BK20170655), and Zhishan Youth Scholar Program of SEU, to which the authors are most grateful.

\section{References}

[1] C. Wu-Jun, L. Yao-Zhi, and F. Gong-Yi, G.-J. Hai and D.S. Lin, A study on space masts based on octahedral truss family," International Journal of Space Structures, vol. 16, no. 1, pp. 75-82, 2001.

[2] B. Sun and Z. Li, "An additional ultra-soft grid method for deformation and kinematic computation of scissor-type structures," International Journal of Mechanical Sciences, vol. 153-154, pp. 230-239, 2019.

[3] B. Sun and Z. Li, "Kinematics analysis of scissor-type inspired interconnects," Acta Mechanica, vol. 230, no. 8, pp. 29792988, 2019.

[4] R. Q. Wu, W. Zhang, and K. Behdinan, "Vibration frequency analysis of beam-ring structure for circular deployable truss antenna," International Journal of Structural Stability and Dynamics, vol. 19, no. 2, Article ID 1950012, 2019.

[5] T. Buhl, F. V. Jensen, and S. Pellegrino, "Shape optimization of cover plates for retractable roof structures," Computers \& Structures, vol. 82, no. 15-16, pp. 1227-1236, 2004.

[6] O. M. Alifanov, A. L. Medvedskiy, V. V. Terentyev, and D. V. Lyskov, "Design experience of a demonstrator descent vehicle introducing aeroelastic deployable structural elements to space engineering," Solar System Research, vol. 52, no. 7, pp. 590-596, 2018.

[7] Y. Chikahiro, I. Ario, M. Nakazawa et al., "Experimental and numerical study of full-scale scissor type bridge," Automation in Construction, vol. 71, pp. 171-180, 2016.

[8] B. Li, S. M. Wang, C. J. Zhi, X. Z. Xue, and V. Makis, "Analytical and numerical study of the buckling of planar linear array deployable structures based on scissor-like element under its own weight," Mechanical Systems and Signal Processing, vol. 83, pp. 474-488, 2017.

[9] G. Wei, X. Ding, and J. S. Dai, "Mobility and geometric analysis of the hoberman switch-pitch ball and its variant," Journal of Mechanisms and Robotics, vol. 2, no. 3, Article ID 031010, 2010.

[10] Y. Sun, S. Wang, J. K. Mills, and C. Zhi, "Kinematics and dynamics of deployable structures with scissor-like-elements based on screw theory," Chinese Journal of Mechanical Engineering, vol. 27, no. 4, pp. 655-662, 2014.

[11] Y. Sun, S. Wang, J. Li, and C. Zhi, "Mobility analysis of the deployable structure of SLE based on screw theory," Chinese Journal of Mechanical Engineering, vol. 26, no. 4, pp. 793-800, 2013.
[12] H. Tanaka, Y. Shibutani, S. Izumi, and S. Sakai, "Planar mobility modes of 8-bar-jointed structures with a single degree of freedom," International Journal of Solids and Structures, vol. 49, no. 13, pp. 1712-1722, 2012.

[13] O. Muvengei, J. Kihiu, and B. Ikua, "Dynamic analysis of planar rigid-body mechanical systems with two-clearance revolute joints," Nonlinear Dynamics, vol. 73, no. 1-2, pp. 259-273, 2013.

[14] S. Faroughi and J. Lee, "Analysis of tensegrity structures subject to dynamic loading using a newmark approach," Journal of Building Engineering, vol. 2, pp. 1-8, 2015.

[15] S. Lee and J. Lee, "A novel method for topology design of tensegrity structures," Composite Structures, vol. 152, pp. 1119, 2016.

[16] S. Kmet and P. Platko, "Adaptive tensegrity module. I: closedform and finite-element analyses," Journal of Structural Engineering, vol. 140, no. 9, Article ID 04014055, 2014.

[17] N. B. H. Ali and I. F. C. Smith, "Dynamic behavior and vibration control of a tensegrity structure," International Journal of Solids and Structures, vol. 47, no. 9, pp. 1285-1296, 2010.

[18] C. Sultan, M. Corless, and R. E. Skelton, "Linear dynamics of tensegrity structures," Engineering Structures, vol. 24, no. 6, pp. 671-685, 2002.

[19] J. Cheong, R. E. Skelton, and Y. Cho, "A numerical algorithm for tensegrity dynamics with non-minimal coordinates," Mechanics Research Communications, vol. 58, pp. 46-52, 2014.

[20] K. Nagase and R. E. Skelton, "Network and vector forms of tensegrity system dynamics," Mechanics Research Communications, vol. 59, pp. 14-25, 2014.

[21] N. D. Oliveto and M. V. Sivaselvan, "Dynamic analysis of tensegrity structures using a complementarity framework," Computers \& Structures, vol. 89, no. 23-24, pp. 2471-2483, 2011.

[22] Y. Ren, Q. Dai, R. An, and Y. Zhu, "Modeling and dynamical behavior of rotating composite shafts with SMA wires," Shock and Vibration, vol. 2014, pp. 1-16, 2014.

[23] J. Cai, Y. Xu, and J. Feng, "Kinematic analysis of hoberman's linkages with the screw theory," Mechanism and Machine Theory, vol. 63, pp. 28-34, 2013.

[24] R. D. Cook, D. S. Malkus, and M. E. Plesha, Concepts and Applications of Finite Elements Analysis, John Wiley \& Sons, Hoboken, NY, USA, 3rd edition, 1998.

[25] K. A. Chopra, Dynamics of Structures-Theory and Application to Earthquake Engineering, Prentice-Hall, Englewood Cliffs, NJ, USA, 1995. 